\title{
Effect of Diet Management on Anxiety in Combat Sports*
}

\section{Efecto de manejar la dieta en la ansiedad en deportes de combate}

Received: 20 April 2018 | Accepted: 06 December 2018

\author{
Alejandro Martínez-Rodríguez \\ Universidad de Alicante, España \\ ORCID: http://orcid.org/0000-0003-4747-3465 \\ Néstor Vicente-Salar \\ Universidad Miguel Hernández de Elche, España \\ ORCID: http://orcid.org/0000-0003-2276-7205 \\ Carlos Montero-Carretero ${ }^{\mathrm{a}}$ \\ Universidad Miguel Hernández de Elche, España \\ ORCID: http://orcid.org/0000-0002-1565-8169 \\ Eduardo Cervelló-Gimeno \\ Universidad Miguel Hernández de Elche, España \\ ORCID: http://orcid.org/0000-0001-5854-6354 \\ ENRIQUe José Roche-Collado \\ Universidad Miguel Hernández de Elche, España \\ ORCID: http://orcid.org/0000-0001-5128-1672
}

a Correspondence author. E-mail: cmontero@goumh.es

How to cite: Martínez-Rodríguez, A., Vicente-Salar, N., Montero-Carretero, C., Cervelló-Gimeno, E., \& Roche-Collado, E. (2019). Effect of diet management on snxiety in combat sports. Universitas Psychologica, 18(2), 1-13. https://doi.org/10.11144/Javeriana.upsy 18-2.edma

\begin{abstract}
Weight control in contact sports implies an additional stress to competitors, mostly when strategies to reduce it are inadequate. The present work analyzes if a correct diet planning could decrease anxiety in competitors. The validated CSAI-2 questionnaire was used before and after the weight control with judo, karate and taekwondo competitors from both genders following a free diet vs those that followed a diet plan. Results indicated that the intensity for somatic and cognitive anxiety in the pre-weight event was lower in male and female competitors following a controlled diet. Regarding gender, no differences in anxiety intensity and directionality were observed between individuals following a free diet in the pre-weight event. Regarding sport discipline, judo and taekwondo practitioners presented higher somatic and cognitive anxiety than karate competitors did. Altogether, the correct control of the corresponding weight throughout the sports season decreases anxiety and increases selfconfidence, allowing to the participants to focus on the contest objectives. Keywords

weight control; diet management; competitive anxiety; combat sports.
\end{abstract}

\section{RESUMEN}

El control del peso en deportes de contacto implica un estrés adicional para los competidores, principalmente cuando las estrategias para bajar de peso son inadecuadas. El presente estudio analiza si un plan adecuado de dieta puede disminuir la ansiedad en los competidores. El cuestionario validado CSAI-2 fue utilizado antes y después del control de peso en judo, karate y taekwondo, competidores de ambos sexos siguieron una dieta libre y fueron contrastados con otros que siguieron un plan de 
dieta. Los resultados indicaron que la intensidad de la ansiedad somática y cognitiva antes del evento de pre peso, fue menor en hombres y mujeres que siguieron una dieta controlada. Respecto al género, no se identificaron diferencias en la intensidad y direccionalidad de la ansiedad entre individuos que siguieron una dieta libre en el evento de pre peso. Respecto al deporte, los practicantes de judo y taekwondo presentaron mayor ansiedad somática y cognitiva que los competidores de karate. En general, el control correcto del correspondiente peso durante de la temporada de deporte disminuye la ansiedad e incrementa la autoconfianza, permitiendo que los participantes se focalicen en los objetivos de la competencia.

Palabras clave

control de peso; gestión de dieta; ansiedad competitiva; deportes de combate.

Traditionally, anxiety has been considered as a negative emotional state (Franklin, Smith, \& Holmes, 2015) that results in the arousal of the autonomous nervous system and therefore, considered an un-adaptive emotional condition. Other authors (Smith, 2008) held anxiety as a psychological response that is produced as a consequence of the discrepancy between the environmental demand and the reaction capacity, which is generally accompanied by a high degree of psycho-physiological activation. According to Cheng, Hardy and Markland (2009) and Englert and Bertrams (2012), anxiety can be considered as somatic (physiological body responses) and cognitive (perceptions undergone by the individual), making a difference between intensity and directionality (Hanton, Neil, \& Mellalieu, 2008). Anxiety intensity corresponds to the severity of the symptoms related to the state, while directionality is referred to the subjective interpretation (facilitative or debilitative) made by the individual of these symptoms (Hanton, Thomas, \& Maynard, 2004).

The presence of anxiety in athletes and how this influences the achievement of certain goals is a complex area of investigation. Some authors interpret anxiety as a debilitating determinant (Englert \& Bertrams, 2012). However, other researchers do not identify anxiety as a negative factor in sports, since they consider that a moderate level of anxiety is beneficial for performance in the activity that competitors have to face (Neil, Wilson, Mellalieu, Hanton, \& Taylor, 2012). Altogether, it seems that the impact of anxiety on sports performance is dependent on the athlete's interpretation (Hill \& Shaw, 2013). These discrepancies could be due to the large amount of factors that can influence the anxiety states of competitors, such as proximity of competition, sport level (Hanton \& Connaughton, 2002; Hanton et al., 2004), and sport discipline (Nieuwenhuys \& Oudejans, 2012).

The proximity of a tournament influences the psycho-physiological state of the competitor negatively, increasing anxiety intensity (Cerin, 2004; Gaudreau, Blondin, \& Lapierre, 2002; Graham, Kowalski \& Crocker, 2002). In this regard, studies are demonstrating the existence of certain personal (age, gender or experience) and environmental (weather conditions or motivational climate) elements that increase anxiety intensity before a competition (Abrahamsen, Roberts \& Pensgaard, 2008; Brunet \& Sabiston, 2008). According to this cognitive-affective perspective, the type and complexity of the sports discipline can induce a state of anxiety (Nieuwenhuys \& Oudejans, 2012). Several studies have shown that the control of specific skills can increase selfconfidence and thereby modulate positively the anxiety states of athletes (Raudsepp \& Kais, 2002). Examples can be found in combat sports where the execution of the correct technique through rapid body movements by hitting or projecting the adversary is necessary to obtain a score. In this context and according to competition rules, the body weight gives an advantage to the heaviest individuals when facing a lighter opponent. To avoid such differences, combat sports are generally distributed into weight categories and to reach an appropriate body weight facilitates a better technical execution.

Therefore, the present work focuses on combat sport disciplines where the athletes are classified into weight categories. In these cases, competitors have to face the day before the competition a strict weight control, being disqualified if they do not enter in the 
corresponding category and throwing away all work performed during the season. Therefore, to achieve a correct weight could be considered as an organizational stressor in combat sport disciplines (Arnold \& Fletcher, 2012). If the correct weight is managed with time in advance at the beginning of the season, the stress is reduced and the competitor can focus mainly on contest objectives. Unfortunately, this schedule is not the general rule, and competitors use to worry about their weight a few weeks before a competition, being thereby more prone to adopt unhealthy dietary strategies. These include forced caloric and water restriction (53\% of competitors), excessive transpiration, self-induced vomiting (4\% of competitors) and the use of diuretics and laxatives (10\% of competitors) (Coufalová, Prokešová, Malý, \& Heller, 2013; Filaire, Rouveix, Pannafieux, \& Ferrand, 2007; Franchini, Brito, \& Artioli, 2012; Kazemi, Shearer, \& Choung, 2005). These strategies can have detrimental physiological (muscle glycogen depletion, dehydration) and psychological impact (incorrect focus on contest objectives) (Pettersson, Ekström, \& Berg, 2013). Therefore, we can hypothesize that this scenario influences negatively in the competitor's anxiety when a tournament approaches.

In combat sports, the ponderal objective is to maintain the highest weight possible in a certain category (Oppliger, Steen \& Scott, 2003). Weight management requires healthy long-term strategies aimed to preserve body muscle while decreasing fat mass (Kubo et al., 2006; SundgotBorgen et al., 2013). These include controlling the energy expenditure of all daily activities, including training sessions. Energy spent after training is replaced immediately by eating a designed diet rich in carbohydrates. Light caloric restriction is applied only in intakes far from training sessions. This strategy can be reinforced with endurance work at the beginning of the season (Martinez-Rodriguez, Vicente-Salar, Montero-Carretero, Cervello, \& Roche, 2015).

Since following a calorie-controlled diet is the healthiest method to achieve correct body weight, we have designed an intervention study to analyze the presence of anxiety in individuals competing in combat sport disciplines before and after the weight control event. To this end, two experimental groups were analyzed and compared; one group followed a supervised nutritional program (intervention group) while the other was allowed a free diet. To our knowledge, this is the first report studying preweight anxiety in combat sports comparing 2 experimental groups (free vs. supervised diet). We hope that the obtained results may provide evidence regarding the importance of diet in managing negative pre-weight anxiety states, thus helping the athletes to focus on their objectives (Arnold \& Fletcher, 2012; Pettersson et al., 2013).

\section{Method}

\section{Participants}

This study was performed with $N=$ 146 volunteers participating in national championships. The total population consisted of 90 men $(M=73.11 \mathrm{~kg}, S D=15.92 ; M=$ 20.70 years, $S D=2.80)$ and 56 women $(M=$ $60.19 \mathrm{~kg}, S D=17.30: M=20.60$ years, $S D$ $=2.60)$, practicing judo $(n=29$ men, $n=24$ women), karate ( $n=30$ men, $n=18$ women), and taekwondo ( $n=31$ men, $n=14$ women). Those that followed a nutritional program for weight control consisted in $n=10$ male judo practitioners $(M=75.75 \mathrm{~kg}, S D=15.32 ; M$ $=21.90$ years, $S D=1.60), n=10$ female judo practitioners $(M=69.88 \mathrm{~kg}, S D=12.34 ; M=$ 21.30 years, $S D=2.40$ years), and $n=10$ male karate practitioners $(M=75.94 \mathrm{~kg}, S D=10.65$; $M=21.70$ years; $S D=4.60)$. The rest of the 116 participants ( $n=70$ men and $n=46$ women) did not follow any diet plan. Therefore, the study groups were referred with the combination of acronyms: J for judo competitors, $\mathrm{K}$ for karate competitors, $\mathrm{T}$ for taekwondo competitors, $\mathrm{M}$ for men and $\mathrm{W}$ for women, $\mathrm{C}$ for the group following a control/free diet and $\mathrm{D}$ for the group following a diet plan.

Due to the need to maintain a diet quality control of participants within the intervention, 
a smaller number of athletes was recruited to this group in comparison to the free diet group. Moreover, due to the lack of volunteers, no taekwondo participants or female karate athletes were recruited to the diet intervention group. In any case, the Kolmogorov-Smirnov test assessed that all intervention groups were following a normal distribution as well as free-diet groups.

Participants were informed about the objectives and demands of the study and gave their written consent to participate. The protocol was under local legal requirements and the Helsinki Declaration for research on human beings and approved by the Project Evaluating Committee of the University. Anonymity was preserved for all participants.

\section{Procedure and Measures}

The Spanish version (Andrade, Lois \& Arce, 2007) of the Competitive State Anxiety Inventory-2Revised (CSAI-2R) (Cox, Martens \& Russell, (2003) was used to determine cognitive anxiety (CA) (fear, panic, obsession, catastrophic thoughts), somatic anxiety (SA) (sweat, increased heart rate, increased muscle tension, pupil dilation, stomach oppression, etc) and self-confidence (SC) (realistic and positive perspective of the athlete). Similar to the studies developed by Martinent, Ferrand, Guillet, and Gautheur (2010), a sub-scale of directionality was added to the original CSAI-2R.

The results obtained from the CSAI-2R were represented concerning intensity and directionality of anxiety. Intensity considers the dimension of CA, SA and SC parameters, while directionality refers to the personal appreciation (facilitative or debilitative) of the athlete and the possible influence on performance (Hanton et al., 2004). The questionnaire has 17 items scaling SA, CA and SC intensities with values between $1-4$ (corresponding to none, low, medium, and high, respectively) and another scale that represents the directionality of the selected values regarding if the state is very debilitative $(0$ to -3$)$ to very facilitative $(0$ to +3 ) with 0 indicating an "unimportant" interpretation. Therefore, symptom perceptions ranged from -27 to +27 for each of the constructs of anxiety and confidence. Cronbach's alpha coefficients have demonstrated internal consistency for the intensity and direction subscales giving values from 0.77 to 0.78 for $\mathrm{CA}$ and SA (Martinent et al., 2010). In our study, Cronbach's alpha varied from 0.72 to 0.75 for intensity scale and from 0.71 to 0.78 for the direction scale.

The questionnaires were distributed in the National University Championships for Judo, Karate and Taekwondo in 2011. The athletes participating in the study filled the questionnaire twice. The first time was $15 \mathrm{~min}$ before the weight control event (considered as the preweight test), which is performed the day before the contest. The second questionnaire was given $15 \mathrm{~min}$ before the warming exercises and referee's control, which is just before the contest (considered the post-weight test).

The mean absolute values obtained for each group were analyzed to compare anxiety intensity and direction of competitors following a free diet vs. a supervised diet. Additionally, a change coefficient (CC) value was established to compare the pre-weight and post-weight tests, allowing intragroup analysis. This is calculated by subtracting the post-weight test results from the pre-weight tests. Negative values indicated that either intensity or directionality was higher in the pre-weight analysis compared to the post-weight. On the contrary, positive values for CC meant that intensity and directionality presented higher values after weight control.

\section{Research Design}

The study consisted of comparing the CSAI-2R scores in groups of participants following a diet plan (JMD, KMD and JWD) after an interventional protocol to a control group that did not undergo any nutritional intervention. This last group was randomly recruited during the University National Championships of judo, karate and taekwondo where diet-intervention groups also participated. 
The nutritional program of the athletes following a controlled diet was based on personalized diets that took in account meal distributions during the day, high protein intakes in meals ingested after training sessions and calorie restriction in meals far from the training sessions (Martinez-Rodriguez et al., 2015). The controlled diet was maintained for at least 2 months. The software used for diet design was DietSourceâ 3.0 (Novartis, Barcelona, Spain).

Caloric expenditure was theoretically estimated and divided into 3 components: resting metabolic rate, the thermal effect of feeding and physical activity expenditure. Resting metabolism was calculated according to the Harris-Benedict equation that takes into account for each gender the weight in $\mathrm{kg}$, height in $\mathrm{cm}$ and the age in years. Corrected body weight was taken into account for calculations, considering ideal weight the upper limit of each weight category in the corresponding disciplines. The thermal effect of food was estimated as $8.50 \%$ of the sum of resting metabolic rate plus physical activity expenditure. The physical activity expenditure was estimated from published tables (Ainsworth et al., 2000).

Diets were adjusted to strength exercises with explosive actions, including 1.60-2.00 $\mathrm{g}$ of protein/day/kg of body weight, $1 \mathrm{~g}$ of fat/day/ $\mathrm{kg}$ of body weight and 5-6 g of carbohydrates/ day $/ \mathrm{kg}$ of body weight (Burd, Tang, Moore \& Phillips, 2009). Daily energy intakes were adapted according to activity and frequency, taking into account training and resting days. For weight reduction, $10-15 \%$ of calorie restriction was applied in meals far from training sessions. Adherence to the intervention was high because, with the diet plan, all individuals of the supervised diet group successfully reached the correct weight with enough time in advance. This reduction was performed from the body fat compartment with no changes at the level of muscle mass.

\section{Data Analysis}

Software SPSS $®$ version 20.0 was used for data analysis. The results were expressed as means (standard deviation). One-sample K-S test (Kolmogorov-Smirnov test) was performed to assess if each variable fits a normal distribution. One-way ANOVA analyzed the data obtained in the different sport disciplines (judo, karate and taekwondo). T-test for independent samples was used to compare means between supervised diet group vs. free diet group (only for JMD, JWD and KMD). Test for related samples was used to compare means in the same group pre-vs. postweight event. Statistical significance was set at $p$ $<0.05$.

\section{Results}

Comparison of anxiety levels between competitors following a supervised diet vs. those on a free-diet

The key question of this study is to compare the anxiety levels of competitors that followed a free diet vs. those on a controlled diet in two critical moments of the contest (pre-weight and precompetition). Although the population studied is very heterogeneous (different disciplines, different weight categories, different gender and different $\mathrm{n}$ ), we can have an overall idea by comparing the free diet vs. the controlled diet group. The statistical analysis performed revealed only significant differences in certain specific parameters.

In this context, the pre-weight intensity of SA presented a score of $1.98(0.62)$ in the free diet group and $1.38(0.09)$ in the diet group, being the difference significant $(p=$ 0.001 ). In addition, the pre-weight directionality of SA significantly $(p=0.004)$ scored 0.29 (0.11) (close to "unimportant") in the free diet group vs. $1.19(0.27)$ (facilitative) in the diet group. This tendency is reflected as well in the pre-weight directionality of SC, displaying a value of $0.89(0.09)$ in the free diet group vs. $1.41(0.17)$ in the diet group with a significant difference $(p=0.013)$. Both pre-weight intensity 
and directionality of CA, as well as pre-weight intensity of SC, gave no significant differences between the analyzed groups.

Regarding the post-weight (pre-competition) situation, the only significant value corresponded to SA intensity with a value of $0.31(0.97)$ for free diet group and $1.44(0.23)$ for the controlled diet group with a significant difference $(p=0.001)$. Finally, the only significant $\mathrm{CC}$ values were those for SA intensity with a $\mathrm{CC}=0.02$ in the free diet group vs a $\mathrm{CC}=0.52$ in the diet group $(p=0.001)$ and CA intensity with a $\mathrm{CC}=$ 0.09 in the free diet group vs. a $\mathrm{CC}=0.54$ in the supervised diet group $(p=0.001)$. However, as stated before, the analyzed groups are very heterogeneous, resulting in very complicate to reach additional conclusions. Therefore, to gain more inside the influence of a supervised diet in anxiety states of competitors, we have performed a similar analysis in the different subpopulations.

Comparison of anxiety levels between competitors following a supervised diet vs. those on a free-diet for the different sport disciplines

To analyze how competitors face the weight control event, those following a supervised diet (JMD, JWD and KMD) were compared to those following a free diet (JMC, JWC and $\mathrm{KMC}$ ). Regarding male judo competitors (Table 1), the results from the CSAI-2 questionnaire performed before weight control (pre-weight event) indicated that the JMC group presented significantly higher SA $(p=0.003)$ and CA $(p=0.007)$ intensities than JMD. This not reflected at the level of SC, which presented no significant differences between JMC and JMD groups (Table 1). Directionality values showed a more facilitative tendency in JMD compared to JMC for SA, CA and SC, although differences between both groups were not significant (Table $1)$.

Regarding female judo athletes (Table 2), the intensity values for SA $(p=0.022)$ and CA $(p=0.013)$ obtained from the pre-weight test were significantly higher in the JWC group compared to JWD, coinciding with the results observed in the male athletes. Besides, SC was considerably higher $(p=0.005)$ in the JWD group. Directionality for SA, CA and SC was more facilitative in the JWD group (Table 2), but with no significant differences compared to JWC.

Following in the context of the pre-weight event, KMC seems to present higher SA and SC intensities and lower CA intensity than $\mathrm{KMD}$, but with no significant differences between both groups (Table 1). Moreover, SA directionality displayed a facilitative tendency in KMD compared to KMC (no significant). No differences for CA and SC directionalities were observed between both groups (Table 1).

Since karate competitors seemed to undergo pre-weight anxiety states differently than judo practitioners, we have included post-weight anxiety in our analysis. When comparing male judo and karate athletes following a free diet, significant differences were observed between pre- $(p=0.012)$ and post-weight $(p=$ 0.029) CA intensity values, and post-weight SA intensity $(p=0.030)$, in which judo athletes always presented significantly higher values than karate competitors. However, in the groups that followed a diet plan for the same sport disciplines, the post-weight CA intensity was higher in KMD group $(p=0.019)$ and post-weight CA directionality was significantly more facilitative in JMD ( $p=0.055)$. In this context, SC intensity in the pre-weight tests was significantly higher in $\operatorname{JMD}(p=0.059)$. 


\section{Table 1}

Scores Obtained in Men after Analysis of Answers from CSAI-2 Questionnaire

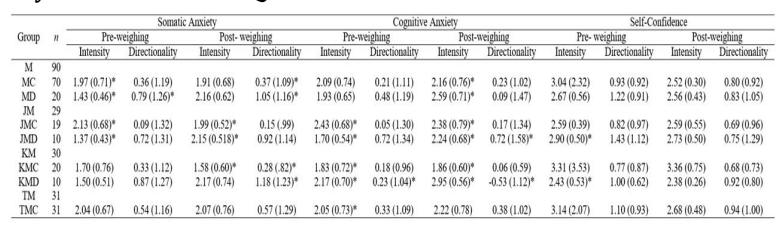

Note Results expressed as mean (standard error of the mean). Somatic Anxiety, Cognitive Anxiety and SelfConfidence correspond to parameters of the CSAI-2 Questionnaire. Pre-weighing corresponds to the test performed before the weight control and Post-weighing corresponds to test performed before the competition. Intensity considers the dimension of CSAI-2 parameters, and Directionality refers to the personal appreciation of the athlete and the possible influence in performance. $\mathrm{M}$ $=$ men; $\mathrm{MC}=$ men control; $\mathrm{MD}=$ men diet; $\mathrm{JM}=$ judo men; JMC = judo men control; JMD = judo men diet; $\mathrm{KM}=$ karate men; $\mathrm{KMC}=$ karate men control; $\mathrm{KMD}=$ karate men diet; TM

$=$ taekwondo men; $\mathrm{TMC}=$ taekwondo men control. *Results significantly different (see text).

\section{Table 2}

Scores Obtained in Women after Analysis of Answers from CSAI-2 Questionnaire

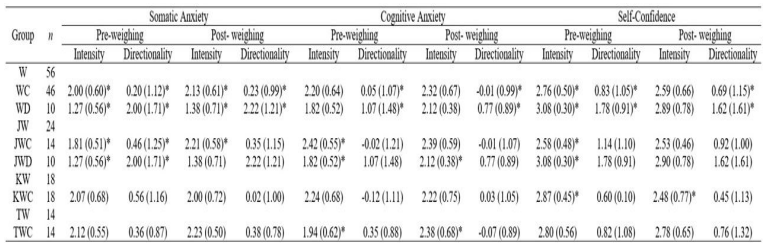

Note Results expressed as mean (standard error of the mean). Somatic Anxiety, Cognitive Anxiety and Self-Confidence correspond to parameters of the CSAI-2 Questionnaire. Preweighing corresponds to the test performed before the weight control and Post-weighing corresponds to the test performed before the competition. Intensity considers the dimension of CSAI-2 parameters, and Directionality refers to the personal appreciation of the athlete and the possible influence in performance. $\mathrm{W}=$ women; $\mathrm{WC}=$ women control; $\mathrm{WD}=$ women diet; JW = judo women; JWC $=$ judo women control; JWD = judo women diet; KW = karate women; KWC = karate women control; TW = taekwondo women; TWC $=$ taekwondo women

control. * Results significantly different (see text).

If male taekwondo competitors were included in the comparison only for free diet groups, two major differences were observed. First, male judo athletes presented significantly higher preweight CA intensities than karate competitors ( $p$ $=0.012$ ), while taekwondo individuals were in between these two groups. Second, post-weight SA intensity was higher in male taekwondo than in karate competitors, with judo athletes presenting intermediate levels $(p=0.036)$. Comparing different sport disciplines, but in the group of women, we observed only that preweight CA intensity was significantly higher in the judo compared to taekwondo competitors $(p=0.042)$, following the same tendency than in men.

These results suggest that some of the participants on a controlled diet (JMD and JWD) experienced less anxiety than those on a free diet, at the time of the weight control event. The CC value could be a good indication of this particular aspect (next section).

Anxiety levels of competitors before and after the weight control event

The CC for SA intensity in the JMC group was -0.14 , being higher in the JMD group (0.78) (Table 1). The negative value of CC indicated that the pre-weight test presented higher SA values in JMC than in the post-weight test, while the opposite was observed in JMD. The same tendency was observed in women with $\mathrm{CC}=$ -0.03 for CA intensity, while the contrary was observed in JWD, CC $=0.30$ (Table 2).

When comparing intra-group individuals for the same sport discipline, it was observed that the JMC group did not present significant differences in SA or CA intensity when analyzing pre- and post-weight tests with a $\mathrm{CC}$ for $\mathrm{SA}=-0.14$ and a $\mathrm{CC}$ for $\mathrm{CA}=-0.05$ (Table 1). On the other hand, the JMD group presented significant differences for SA $(p=0.002)$ and CA $(p=$ $0.014)$ intensities in the pre-weight test results, which were lower compared to the post-weight test with a $\mathrm{CC}$ for $\mathrm{SA}=0.78$ and a $\mathrm{CC}$ for $\mathrm{CA}=$ 0.54 (Table 1). In the case of the JWC group, only SA intensity presented a significant difference ( $p$ $=0.020$ ), where the values obtained in the postweight test were higher compared to pre-weight with a $\mathrm{CC}=0.40$ (Table 2 ). In the JWD group, CA intensity increased significantly $(p=0.007)$ in the post-weight test with a $\mathrm{CC}=0.30$ (Table 
2). It seems likely that both groups (JWD and JWC) approached the competition differently. In support of this, post-weight directionality of SA presented a significant more facilitative score in the JWD compared to the JWC $(p=0.001)$, while the post-weight intensity of SA was higher in the JWC group $(p=0.005)$.

In male karate athletes (Table 1), the significant differences between $\mathrm{KMC}$ and $\mathrm{KMD}$ groups occurred only in the post-weight test. KMD presented significant higher SA intensity $(p=0.028)$, more facilitative directionality $(p$ $=0.054)$ and higher CA intensity $(p=0.001)$ compared to KMC. This is supported by the observation that the KMD group presented significant CC differences for SA $(p=0.001)$ with a $C C=0.67$ and $C A(p=0.002)$ with a $\mathrm{CC}=0.78$. Nevertheless, CA directionality $\mathrm{CC}$ values $(\mathrm{CC}=-0.76)$ were also significantly different (Table 1) $(p=0.046)$. In the KWC group, SC intensity values lowered in the postweight test (Table 2) $(p=0.007)$ with a CC $=-0.39$. Finally, the CA intensity in the TWC group increased in the post-weight test (Table 2) $(p=0.043)$ with a $\mathrm{CC}=0.44$.

Therefore, the results suggest that to follow a supervised diet seems to help a part of individuals of this study to experience lower pre-competition anxiety than those on a free diet. To complete this information, we have pooled data from the different groups and analyzed the influence of a supervised diet vs. a free diet on anxiety states.

\section{Influence of gender in anxiety states}

ooling all groups, male competitors that followed a free diet $(\mathrm{MC})$ presented higher SA intensity values in the pre-weight test compared to those that followed a diet plan (MD) $(p=$ 0.002 ). In the post-weight tests, CA intensity was significantly increased $(p=0.025)$ and SA directionality displayed a significant facilitative score $(p=0.018)$ in MD compared to MC (Table $1)$.

Regarding the female athletes, SA intensity was higher in the pre-weight tests of the free diet group (WC) compared to those following a controlled diet plan (WD) $(p=0.001)$. Preweight SA directionality displayed a significant facilitative score $(p=0.001)$ in WD compared to WC. This is confirmed by the observation that pre-weight CA $(p=0.014)$ and SC $(p=$ $0.011)$ directionalities presented more facilitative scores, as well as SC intensity was significantly higher $(p=0.057)$ in the WD group. The tendency was maintained post-weight in WC for SA intensity $(p=0.001)$, SA directionality $(p$ $=0.001)$, CA directionality $(p=0.026)$ and SC directionality $(p=0.036)$ compared to WD.

Comparing both genders, the females that followed a diet plan presented more facilitative scores for SA directionality compared to males both in pre- $(p=0.036)$ and post-weight tests $(p$ $=0.016)$. The same was true for SC intensity in the pre-weight test $(p=0.036)$. However, postweight SA intensity was significantly higher in men than in women on a diet plan $(p=0.005)$. Also, male competitors following a diet presented higher CA intensities than females $(p=0.024)$.

\section{Discussion}

The main goal of the present study has been to analyze the presence of anxiety in individuals competing in contact sport disciplines in the particular moment of the pre-weight control event, considering that a supervised diet will determine a more positive interpretation of anxiety symptoms. To see if this particularity influences the participant's anxiety, we have measure anxiety levels just in the pre-weight event and compared to the pre-competition moment (post-weight event) in 2 populations of competitors, those that followed a free diet and those that followed a supervised diet by a certified nutritionist.

The obtained results strongly indicated that those individuals on a supervised diet during the season arrived at the weight control event with lower values of SA intensity and more facilitative scores of SA directionality than those individuals on a free diet. However, significant differences were not observed when CA parameters (intensity and directionality) 
were analyzed between both groups. A possible explanation is that CA represents a more subjective interpretation of anxiety and the heterogeneity of the overall populations analyzed so far (different sport disciplines, different weight categories, different genders and different n) could explain the lack of significance. Nevertheless, the analysis of the different subpopulations allowed to gain in homogeneity, giving more significant results.

In this context, the pattern observed, at least in judo practitioners (men and women), is that anxiety increases significantly in the preweight event in individuals following a free diet, except karate competitors. Additionally, judo and karate competitors following a supervised diet underwent higher levels of pre-competition (post-weight) anxiety compared to the anxiety undergone in the pre-weight event $(\mathrm{CC}=0.78$ for JMD and $\mathrm{CC}=0.67$ for $\mathrm{KMD}$ ). The anxiety experienced was in very similar ranges that the anxiety observed for the corresponding free diet groups (JMC and $\mathrm{KMC}$ ). This corresponds to precompetitive anxiety, and it seems that diet has a more positive influence in the SA directionality (more facilitative in the diet groups) and CA intensity than in SA intensity.

The question that could arise is if high precompetitive anxiety could be beneficial in combat sports. First, previous studies indicated that this increased level of anxiety is related to hormonal responses (Parmigiani et al., 2009) that could prepare the organism for competition. However, there are multiple theories to explain how different anxiety parameters may affect performance. Several studies indicated that decreasing anxiety and increasing SC could improve the athlete's results (Mullen \& Tattersall, 2005). On the other hand, certain authors indicated that it was possible to obtain optimal results by maintaining anxiety at intermediate levels (Gould, Greenleaf, \& Krane, 2002). In any case, our results indicate that the athletes following a controlled diet program presented only pre-competition anxiety, which should most likely be due to the fact that weight control could not be considered as an additional stress factor. A hypothetical interpretation that needs to be verified in the future is that competitors following a controlled diet could be more focused on the tournament than in the weight control event.

Nevertheless, this general assumption was not exactly extensive for certain specific groups: women judoists and karate competitors. In women, post-weight SA intensity was higher than pre-weight in JWC. The same tendency was observed for CA intensity in JWD, presenting as well more facilitative post-weight SA directionality. In this context, the evaluation of directionality performed by athletes is a reliable indicator of sports performance and helps establish a positive relationship between CA, SA and SC (Cheng, Hardy, \& Woodman, 2011; Hanton et al., 2004). Also, women competitors following a controlled diet program presented significantly higher self-confidence values. Altogether, these results indicate that a controlled diet has beneficial effects at the somatic-cognitive level with increased selfconfidence values.

In any case, comparing genders, some authors indicated that women present higher CA and lower SC (Hanton et al., 2004) than men. However, in a more recent study, the female athletes following a controlled diet program presented higher SC intensities compared to men, possibly indicating that women confront the challenge to reach an appropriate weight in a more positive manner (Oppliger et al., 2003). This is a crucial observation since women are generally more prone to adopt inadequate strategies to lose weight (Baum, 2006). In our study, the female competitors following a free diet presented lower SA intensity and less facilitative SC directionality in the post-weight event compared to males, indicating better cognitive and physiological control towards the contest. These parameters, along with a more facilitative SA directionality, seem to correlate with a sympathetic activation which overall results in increased sports success (Hanton et al., 2004).

Regarding karate competitors, a possible explanation for the observed results is that competitors of Olympic disciplines (judo and 
taekwondo) could suffer higher levels of anxiety, considering most likely each contest as a transcendental situation for their sports career. In this context, both JMC and TMC groups presented higher anxiety levels (both SA and CA in the case of judo, and only SA in the case of taekwondo) compared to the KMC group. In any case, further work is necessary to study in more detail these particular points.

\section{Conclusions and limitations}

Competitors that do not follow a controlled diet program seem to present increased levels of somatic and cognitive anxiety when a tournament approaches, focusing mainly on the pre-weight event and not in the contest itself. Therefore, and as an applied implication, the use of an adequate nutritional control during the sports season preserves the health of competitors and reduces their stress levels, allowing them to concentrate more fully on the competition. In this context, it could be essential to provide the coaches with tools that will enable them to detect anxiety states in competitors, identifying at the same time if diet accomplishment could be acting as a stressor. At the same time, the work of nutrition professionals has to be considered as well, to avoid unhealthy diet strategies such as extreme caloric or liquid restrictions that can compromise competitors' health and likely their own life.

However, this work presents some limitations that need to be considered. First, we have to study the possibility of inducing adequate nutritional habits in competitors following a free diet. Second, we have to equilibrate the number of participants in both groups, regarding sport discipline, gender and competitive level. Third, it could be interesting to consider additional variables that can modulate the anxiety levels of competitors, such as experience or number of success/defeats. Finally, and fourth, it could be interesting to follow competitors of both groups (free and supervised diet) during the season, including training sessions and not only during the contest day. This last could help to find factors that can modulate anxiety states in the moment of facing the competition.

\section{References}

Abrahamsen, F. A., Roberts, G. C., \& Pensgaard, A. M. (2008). Achievement goals and gender effects on multidimensional anxiety in national elite sport. Psychology of Sport and Exercise, 9(4), 449-464. https://doi.org/ 10.1016/j.psychsport.2007.06.005

Ainsworth, B. E., Haskell, W. L., Whitt, M. C., Irwin, M. L., Swartz, A. M., Strath, S. J., ... Leon, A. S. (2000). Compendium of physical activities: an update of activity codes and MET intensities. Medicine and Science in Sports and Exercise, 32 (9), S498. S504. https://doi.org/10.1097/00005768-20 0009001-00009

Andrade, E. M., Lois, G., \& Arce, C. (2007). Propiedades psicométricas de la versión española del inventario de ansiedad competitiva CSAI-2R en deportistas [Psycometrist properties of the spanish version of the Competitive State Anxiety Inventory CSAI-2R in sportmen]. Psicothema, 19(1), 150-155. Retrieved from http://www.psicothema.com/psicothe ma.asp? id $=3341$

Arnold, R., \& Fletcher, D. (2012). A research synthesis and taxonomic classification of the organizational stressors encountered by sport performers. Journal of Sport and Exercise Psychology, 34(3), 397-429. https:// doi.org/10.1123/jsep.34.3.397

Baum, A. (2006). Eating disorders in the male athlete. Sports Medicine, 36(1), 1-6. https://doi.org/10.2165/0007256-2006 36010-00001

Brunet, J., \& Sabiston, C. M. (2008). Social physique anxiety and physical activity: A selfdetermination theory perspective. Psychology of Sport and Exercise, 10, 329-335. https://doi.org/10.1016/j.psychsp ort.2008.11.002

Burd, N. A., Tang, J. E., Moore, D. R., \& Phillips, S. M. (2009). Exercise training 
and protein metabolism: influences of contraction, protein intake, and sex-based differences. Journal of Applied Physiology, 106(5), 1692-1701. https://doi.org/10.1152 /japplphysiol.91351.2008

Cerin, E. (2004). Predictors of competitive anxiety direction in male taekwondo practitioners: a multilevel mixed idiographic/nomothetic interactional approach. Psychology of Sport and Exercise, 5(4), 497-516. https://doi.org/ 10.1016/S1469-0292(03)00041-4

Cheng, W. N., Hardy, L., \& Markland, D. (2009). Toward a three-dimensional conceptualization of performance anxiety: Rationale and initial measurement development. Psychology of Sport and Exercise, 10(2), 271-278. https://doi.org/10. 1016/j.psychsport.2008.08.001

Cheng, W. N., Hardy, L., \& Woodman, T. (2011). Predictive validity of a three-dimensional model of performance anxiety in the context of taekwondo. Journal of Sport and Exercise Psychology, 33, 40-53. Retrieved from https://pdfs.semanticscholar.org/2c54 /73a594cfceded1a4e4dbb0cb02b909f5668 7.pdf

Coufalová, K., Prokešová, E., Malý, T., \& Heller, J. (2013). Body weight reduction in combat sports. Archives of Budo 9(4), 267-272. Retrieved from http://archbudo.com

Cox, R. H., Martens, M. P., \& Russell, W. D. (2003). Measuring anxiety in athletics: The revised Competitive State Anxiety Inventory-2. Journal of Sport and Exercise Psychology, 25(4), 519-533. Retrieved from https://psycnet.apa.org/reco $\mathrm{rd} / 2003-10604-007$

Englert, C., \& Bertrams, A. (2012). Anxiety, ego depletion, and sports performance. Journal of Sport and Exercise Psychology, 34(5), 580-599. Retrieved from https://pdfs.semanticscholar.org/734f/ 97b1d420b3e2af54609b1b3bd29c6213a7d 4.pdf

Filaire, E., Rouveix, M., Pannafieux, C., \& Ferrand, C. (2007). Eating attitudes, perfectionism and body-esteem of elite male judoists and cyclists. Journal of Sports Science and Medicine, 6(1), 50-57. Retrieved from https://www.ncbi.nlm.nih.gov/pmc/ar ticles/PMC3778699/

Franchini, E., Brito, C. J., \& Artioli, G. (2012). Weight loss in combat sports : physiological, psychological and performance effects. Journal of the International Society of sports Nutrition, 9, 52. https://doi.org/10.1186/15 50-2783-9-52

Franklin, Z. C., Smith, N. C., \& Holmes, P. S. (2015). Anxiety symptom interpretation and performance expectations in highanxious, low anxious, defensive highanxious and repressor individuals. Personality and Individual Differences, 77, 27-32. https://doi.org/10.1016/j.paid.2014. 12.040

Gaudreau, P., Blondin, J. P., \& Lapierre, A. M. (2002). Athletes' coping during competition: relationship of coping strategies with positive affect, negative affect, and performance-goal discrepancy. Psychology of Sport and Exercise, 3(2), 125-150. https://doi.org/10.1016/S1469-02 92(01)00015-2

Gould, D., Greenleaf, C., \& Krane, V. (2002). The arousal-athletic performance relationship: Current status and future directions. In T. S. Horn (Ed.), Advances in sport psychology (2nd ed) (pp. 207-241). Champaign, IL: Human Kinetics.

Graham, T. R., Kowalski, K. C., \& Crocker, P. R. E. (2002). The contributions of goal characteristics and causal attributions to emotional experience in youth sport participants. Psychology of Sport and Exercise, 3(4), 273-291. https://doi.org/10.1 016/S1469-0292(01)00006-1

Hanton, S., \& Connaughton, D. (2002). Perceived control of anxiety and its relationship to self-confidence and performance. Research Quaterly for Exercise and Sport, 73(1), 87-97. https://doi.org/10.1 080/02701367.2002.10608995

Hanton, S., Neil, R., \& Mellalieu, S. D. (2008). Recent developments in competitive anxiety direction and competition stress 
research. International Review of Sport and Exercise Psychology, 1(1), 45-57. https://doi. org/10.1080/17509840701827445

Hanton, S., Thomas, O., \& Maynard, I. (2004). Competitive anxiety responses in the week leading up to competition: the role of intensity, direction and frequency dimensions. Psychology of Sport and Exercise, 5(2), 169-181. https://doi.org/10.1016/S14 69-0292(02)00042-0

Hill, D. M., \& Shaw, G. (2013). A qualitative examination of choking under pressure in team sport. Psychology of Sport and Exercise, 14(1), 103-110. https://doi.org/10.1016/j.ps ychsport.2012.07.008

Kazemi, M., Shearer, H., \& Choung, Y. S. (2005). Pre-competition habits and injuries in taekwondo athletes. BMC Musculoskeletal Disorders, 6, 26. https://doi.org/10.1186/14 71-2474-6-26.

Kubo, J., Chishaki, T., Nakamura, N., Muramatsu, T., Yamamoto, Y., Ito, M., ... Kukidome, T. (2006). Differences in fat-free mass and muscle thicknesses at various sites according to performance level among judo athletes. Journal of Strength and Conditioning Research, 20(3), 654-657. https://doi.org/10 $.1519 / \mathrm{R}-17054.1$

Martinent, G., Ferrand, C., Guillet, E., \& Gautheur, S. (2010). Validation of the French version of the Competitive State Anxiety Inventory-2 Revised (CSAI-2R), including frequency and direction scales. Psychology of Sport and Exercise, 11(1), 51-57. Retrieved from http://www.journals.elsevier.com/psyc hology-of-sport-and-exercise/

Martinez-Rodriguez, A., Vicente-Salar, N., Montero-Carretero, C., Cervello, E., \& Roche, E. (2015). Nutritional strategies to reach the weight category in judo and karate athletes. Archives of Budo, 11(1), 381-391. Retrieved from http://archbudo.c om/view/abstract/id/10836

Mullen, R., \& Tattersall, A. (2005). The effects of anxiety on motor performance: A test of the conscious processing hypothesis. Journal of Sport and Exercise Psychology,
27(2), 212-225. Retrieved from http://jour nals.humankinetics.com/jsep

Neil, R., Wilson, K., Mellalieu, S. D., Hanton, S., \& Taylor, J. (2012). Competitive anxiety intensity and interpretation: A two-study investigation into their relationship with performance. International Journal of Sport and Exercise Psychology, 10(2), 96-111. https ://doi.org/10.1080/1612197X.2012.645134

Nieuwenhuys, A., \& Oudejans, R. R. D. (2012). Anxiety and perceptual-motor performance: toward an integrated model of concepts, mechanisms, and processes. Psychological Research, 76(2), 747-759. http s://doi.org/10.1007/s00426-011-0384-x

Oppliger, R. A., Steen, S. A., \& Scott, J. R. (2003). Weight loss practices of college wrestlers. International Journal of Sport Nutrition and Exercise Metabolism, 13(1), 117-121. Retrieved from http://journals.hu mankinetics.com/ijsnem

Parmigiani, S., Dadomo, H., Bartolomucci, A., Brain, P. F., Carbucicchio, A., Costantino, C., ... Volpi, R. (2009). Personality traits and endocrine response as possible asymmetry factors of agonistic outcome in karate athletes. Aggressive Behavior, 35(4), 324-333. https://doi.org/10.1002/ab.20306

Pettersson, S., Ekström, M. P., \& Berg, C. M. (2013). Practices of weight regulation among elite athletes in combat sports: A matter of mental advantage? Journal of Athletic Training, 48(1), 99-108. https://doi. org/10.4085/1062-6050-48.1.04

Raudsepp, L., \& Kais, K. (2002). The relationship between state anxiety and performance in beach voleyball players. Journal of Human Movement Studies, 43(5), 403-416. Retrieved from http://www.jhmsonline/100488246

Smith, R. E. (2008). Advances in the cognitivesocial theory of personality: Applications in Sport Psychology. Revista de Psicología del Deporte, 17(2), 253-276. Retrieved from ht tps://www.rpd-online.com/article/view/7

Sundgot-Borgen, J., Meyer, N. L., Lohman, T. G., Ackland, T. R., Maughan, R. J., Stewart, A. D., \& Müller, W. (2013). 
How to minimise the health risks to athletes who compete in weight-sensitive sports review and position statement on behalf of the Ad Hoc Research Working Group on Body Composition, Health and Performance, under auspices of the IOC Medical Commission. British Journal of Sports Medicine, 47(16), 1012-1022. https:/ /doi.org/10.1136/bjsports-2013-092966

\section{Notes}

* Research article. This project was financed by the PROMETEO grant (2016/006) from Generalitat Valenciana to ER. 